\title{
Structure-induced microalloying effect in multicomponent alloys
}

Gu-Qing Guo ${ }^{1}$, Liang Yang ${ }^{1, *}$, Shi-Yang Wu ${ }^{1}$, Qiao-Shi Zeng ${ }^{2,3, *}$, Cheng-Jun Sun ${ }^{4}$, and Yin-Gang Wang ${ }^{1}$

${ }^{1}$ College of Materials Science and Technology, Nanjing University of Aeronautics and Astronautics, Nanjing 210016, P.R. China

${ }^{2}$ Center for High Pressure Science and Technology Advanced Research (HPSTAR), 1690 Cailun Road, Pudong, Shanghai 201203, P.R. China

${ }^{3}$ HPSynC, Geophysical Laboratory, Carnegie Institution of Washington, 9700 South

Cass Avenue, Argonne, Illinois 60439, USA

${ }^{4}$ Advanced Photon Source, Argonne National Laboratory, Argonne, Illinois 60439, USA

\section{Abstract}

In this work, the microalloying effect on glass-forming ability (GFA) has been investigated from the structural aspect, by performing synchrotron radiation x-ray diffraction and absorption measurements coupled with simulations in the NiNbZr ternary system. By sorting out the preferred Voronoi clusters, we propose a new structural parameter which counts the fraction of the five-connected shell atoms in clusters and find it is strongly associated with the GFA. In particular, this structural parameter has the highest value in a composition where the best GFA is achieved. The present work provides an in-depth understanding of microalloying-induced high GFAs in multicomponent alloys.

Authors to whom correspondence should be addressed: electronic mail: yangliang@nuaa.edu.cn and qzeng@carnegiescience.edu

Key words: bulk metallic glass; glass-forming ability; synchrotron radiation; shortrange ordering; Monte Carlo simulation; microalloying 


\section{Introduction}

In principle, the melt of any substance, can be frozen into a disordered solid called glass if cooled rapidly enough. For the metallic glass (MG) systems, the minimum cooling rate required for glass forming ranges from $10^{-1} \mathrm{~K} / \mathrm{s}$ up to $10^{6} \mathrm{~K} / \mathrm{s}$ [1], which sets the good glass forming ability (GFA) systems apart from the marginal systems. Searching for optimized compositions with good GFA particularly in multicomponent MGs has been attracting a lot of efforts over decades, but so far it is still largely based on a strategy of trial and error in multidimensional composition space without effective guidance of any general theory [2-10]. The GFA has been found to be extremely sensitive to compositions even with minor variation of the composition [11,12]. Based on this phenomenon, a practical empirical rule called "microalloying" $[13,14]$ has been widely used to facilitate the development of new MGs with improved GFA [15-19]. Nevertheless, the mechanism of this microalloying effect on GFA remains elusive.

Structure determines properties of materials. Understanding the GFA of MGs from the structural perspective is critical and has been pursued for decades [20-25]. Although the explicit overall structural picture of MGs has not been resolved, local atomic and/or cluster structural models have been established. For example, several structural models have been proposed by building and stacking clusters to fill space efficiently, including the hard-sphere random-packing model [26], the stereochemically designed model [27], the cluster packing model [28], and the quasiequivalent clusters model [29]. These structural models can statistically describe the intrinsic short-to-medium range ordering in MGs with simple compositions very well. Experiments revealed that the microalloying-enhanced GFA of multicomponent alloys usually has a local maximum in a pinpoint composition [13]. This is associated 
with fine structural changes in such pinpoint composition [30] which however could not been well described in the existing theoretical structure models. Therefore, further studies are required to address this issue.

\section{Experimental and simulation methods}

In this work, $\mathrm{Zr}$-doped $\mathrm{NiNb}$ ternary MGs is chosen as a model system because there is a typical pinpoint composition enable formation of relatively high GFA [31,32]. Here $\mathrm{Ni}_{62} \mathrm{Nb}_{38-\mathrm{x}} \mathrm{Zr}_{\mathrm{x}}(\mathrm{x}=1,3,5,7$, and 9) compositions are selected. Except that $\mathrm{Ni}_{62} \mathrm{Nb}_{33} \mathrm{Zr}_{5}$ has a critical casting size larger than $3 \mathrm{~mm}$ in diameter, other four compositions have critical sizes of 1-2 $\mathrm{mm}$. All the alloy ingots were fabricated by arc melting mixtures of constituent elements [Ni (99.95 wt.\%), $\mathrm{Nb}(99.9 \mathrm{wt} \%$ ), and $\mathrm{Zr}$ (99.9 wt.\%)] in Ti-gettered high purity argon atmosphere. These ingots were melted at least 5 times so that their compositional homogeneity could be ensured. Subsequently, the ribbon sample with the thickness of $20-30 \mu \mathrm{m}$ of each composition was prepared by employing the melt-spinning technique.

Without long range periodic symmetry, the structure of MGs is challenging to be determined by experimental tools. Fortunately, synchrotron radiation-based x-ray diffraction (XRD) and extended x-ray absorption fine structure spectroscopy (EXAFS) are two dedicated probes for amorphous structure. In this work, to get relatively large Q (wave vector transfer) value in reciprocal space, high-energy (86 keV) XRD measurements were carried out for all ribbon samples at the beam line, Sector $1 \mathrm{ID}$, of the Advanced Photon Source in USA. Ni and Nb K-edge EXAFS spectra were measured at the beam lines, BL14W1, in the Shanghai Synchrotron Radiation Facility of China, Sector $20 \mathrm{BMB}$, in the Advanced Photon Source of USA, and U7C, in National Synchrotron Radiation Laboratory (NSRL) of China. We could not measure high signal-to-noise EXAFS spectra for Zr K-edge, because its extended-edge data 
overlaps with the background of $\mathrm{Nb}$ K-edge absorption signal. Both the XRD and the EXAFS raw data were normalized via a standard data-reduced procedure, employing the Fit2D [33], the PDFgetX [34], and the Visual Processing in EXAFS Researches (VIPER) [35], respectively.

We then performed reverse Monte Carlo (RMC) simulation [36,37] on XRD data combined with $\mathrm{Ni}$ and $\mathrm{Nb} \mathrm{K}$-edge EXAFS data simultaneously to extract atomic structural information by using the software RMCA [38]. RMC has been confirmed to be a reliable method to get the atomic structure of MGs [29] The structural models (cubic boxes) containing 40,000 random-distributed $\mathrm{Ni}, \mathrm{Nb}$, and $\mathrm{Zr}$ atoms were built and used in this RMC simulation, matching the $\mathrm{Ni}_{62} \mathrm{Nb}_{38-\mathrm{x}} \mathrm{Zr}_{\mathrm{x}}(\mathrm{x}=1,3,5,7$, and 9) compositions. The atomic densities and lengths of boxes of $\mathrm{Ni}_{62} \mathrm{Nb}_{38-\mathrm{x}} \mathrm{Zr}_{\mathrm{x}}(\mathrm{x}=1,3,5$, 7, and 9) are $0.0730 \AA^{-3}, 0.0724 \AA^{-3}, 0.0719 \AA^{-3}, 0.0714 \AA^{-3}$, and $0.0708 \AA^{-3}$, and $75.98 \AA$, $76.16 \AA, 76.35 \AA, 76.52 \AA$, and $76.73 \AA$, respectively. During RMC simulation, atoms move randomly within a determined time interval. The experimental data are compared to the simulation with an iterative calculation [39]:

$$
\delta^{2}=\frac{1}{\varepsilon^{2}} \sum_{n}\left(S_{m}\left(Q_{n}\right)-S_{\exp }\left(Q_{n}\right)\right)^{2}+\frac{1}{\varepsilon_{i}^{2}} \sum_{n}\left(\chi_{m, E l}\left(\kappa_{n}\right)-\chi_{\exp , E l}\left(\kappa_{n}\right)\right)^{2}
$$

where $\delta^{2}$ represents the deviation between the experimental and simulation data, $\varepsilon$ parameters regulate the weight of the data set given in the fitting procedure, $E_{i}$ denotes the $\mathrm{Ni}, \mathrm{Nb}$, and $\mathrm{Zr}$ elements, and the $\mathrm{S}(\mathrm{Q})$ and $\chi(\kappa)$ parameters are the XRD structural factor in Q space and EXAFS signal, respectively. The subscripts " $\mathrm{m}$ " and "exp" represent the simulations and experiments, respectively. S(Q) can be obtained by:

$$
S_{m}(Q)=\sum_{i j} w_{i j}(Q) S_{i j}(Q)
$$


where $S_{\mathrm{ij}}(\mathrm{Q})$ and $\mathrm{w}_{\mathrm{ij}}$ are the partial $\mathrm{S}(\mathrm{Q})$ and their weights, respectively. $\mathrm{S}_{\mathrm{ij}}(\mathrm{Q})$ can be calculated by:

$$
S_{i j}(Q)=\frac{4 \pi \rho}{Q} \int r \sin Q r\left(g_{i j}(r)-1\right) d r
$$

where $\rho$ and $r$ are the average number density and interatomic distance, respectively. $\mathrm{g}_{\mathrm{ij}}(\mathrm{r})$ is the partial pair distribution function. Thus, the relation between real space $\mathrm{g}(\mathrm{r})$ and reciprocal space $\mathrm{S}(\mathrm{Q})$ is presented. The theoretical EXAFS signal $\chi(\kappa)$, of the ith element is calculated from the following equation:

$$
\chi_{m, i}(\kappa)=\sum_{j} 4 \pi c_{j} \rho \int r^{2} \gamma_{i j}(r, \kappa) g_{i j}(r) d r
$$

where $\mathrm{cj}$ is the concentration of the jth element and $\gamma_{\mathrm{ij}}$ can be calculated by:

$\gamma_{i j}(r, \kappa)=A_{i j}(\kappa, r) \sin \left(2 \kappa r+\Phi_{i j}(\kappa r)\right)$

where Aij and $\Phi \mathrm{ij}$ denote the amplitude and the phase shift, respectively. They can be obtained by using the FEFF 8.1 code [39].

After each run, if $\delta_{\text {new }}^{2}<\delta^{2}$, the move is accepted. Otherwise, it is accepted with a probability of $\exp \left[-\left(\delta_{\text {new }}^{2}-\delta^{2}\right) / 2\right]$. In our case, to enable the movement of atoms while avoid the strong overlap between neighbor atoms, the cut-off distances between Ni-Ni, Ni-Nb. Ni-Zr, Nb-Nb, Nb-Zr, and Zr-Zr atomic pairs are set as $2.14 \AA$, $2.28 \AA$, $2.43 \AA, 2.57 \AA, 2.57 \AA$, and $2.72 \AA$, respectively. Once the simulation and experimental data converge, the simulation is stopped, and all the atoms are preserved and "frozen" in the cubic box, forming a structural model available for further analyses.

Moreover, the RMC simulated structural models were further analyzed by Voronoi-tessellation method [40,41]. According to the Voronoi original algorithm, each convex Voronoi polyhedron (VP) can be built by connecting the perpendicular 
bisectors between a center atom and all of its neighboring atoms. Each VP may be indexed as $\langle\mathrm{n} 3, \mathrm{n} 4, \mathrm{n} 5, \mathrm{n} 6, \ldots>$, where $n i$ denotes the number of i-edged faces on the surface of this polyhedron. Each VP should be embedded in a corresponding convex Voronoi cluster (VC), made up of one center atom and its neighboring shell atoms Thus, $\sum n i$ also stands for the number of the shell atoms in one $\mathrm{VC}$, i.e., the coordination number $(\mathrm{CN})$ of the center atom. The Voronoi algorithm also requires that all VCs should be closed structural units, which can be accomplished by piling up a set of Delaunay tetrahedrons with the common vertex at an atom (the center atom of VC) [29], so that it shell is made up of only triangles faces. We show the configuration of a typical icosahedral $\mathrm{VC}<0,0,12,0\rangle$ and its corresponding VP in Fig. 1. Here we emphasize that a VP has no shell atom located at its vertices while a VC has (configurations of more VCs and corresponding VPs, refer to Fig. 6 of Ref. 40 and Fig. 1 in Ref. 42). It is worth noting that for $\langle 0,0,12,0\rangle$ index, its VC has 12 fiveconnected shell atoms, and its VP has 12 pentagons, which are the middle sections between the center and a shell atom in a corresponding VC.

\section{Results and discussion}

Figs. 2(a)-2(d) show the XRD (structural factor, S(Q) and total pair distribution function, G(r)) and EXAFS data, as well as their simulated curves. No sharp Bragg peak is present in the $S(Q)$ curves, which adequately indicates the full amorphous nature in all the samples [43]. The good matching between the experimental XRD (EXAFS) data and their simulated curves confirms the reliability of the RMC simulation. It should be noted that although during the RMC simulation, the simulated experimental data do not include that of $\mathrm{Zr}$ K-edge EXAFS, we can still get reliable structural information, because of the following reasons: 1) EXAFS is an elementspecific method available for measuring the surroundings of each kind of atoms. In 
other words, all the neighbor atoms around each atom can be distinguished when EXAFS data is fitted or simulated [44]. Since Ni and Nb EXAFS data can reflect all of their neighborhood information containing $\mathrm{Ni}, \mathrm{Nb}$, and $\mathrm{Zr}$ atoms, how the $\mathrm{Zr}$ atoms distribute around the $\mathrm{Ni}(\mathrm{Nb})$ centers can accordingly be determined; 2) three independent sets of experimental data (one set of XRD and two sets of EXAFS (Ni and $\mathrm{Nb}$ ) ) were simultaneously simulated in this work. During the RMC simulation, all of these experimental data should be fitted with their counterparts calculated theoretically from the same structural model. Such constraint can eliminate the computational randomness.

Fig. 3 shows the partial $\mathrm{g}(\mathrm{r}) \mathrm{s}$ obtained from the RMC simulation. The $\mathrm{r}$ resolution (dr) for the $\mathrm{g}(\mathrm{r}) \mathrm{s}$ shown here is $0.125 \AA$. We can see that except for the $\mathrm{Zr}$ $\mathrm{Zr}$ pair which has a relatively random distribution due to the low concentrations of $\mathrm{Zr}$ in these alloys (in particular in $\mathrm{Ni}_{62} \mathrm{Nb}_{37} \mathrm{Zr}_{1}$ ), other atomic pairs such as $\mathrm{Ni}-\mathrm{Ni}, \mathrm{Ni}-\mathrm{Nb}$, $\mathrm{Ni}-\mathrm{Zr}, \mathrm{Nb}-\mathrm{Nb}$, and $\mathrm{Nb}-\mathrm{Zr}$ have the broad distributions from 2.1-3.1 $\AA$, 2.3-3.3 $\AA$, 2.33.5 $\AA$, 2.4-3.5 $\AA$, and 2.5-3.5 $\AA$, respectively. From the RMC simulated model, the atomic-scale structural information including the first-shell CNs and the atomic pair distances could be deduced. They are listed in Table 1 and Table 2. It seems that there is no obvious difference of atomic pair distances between these five NiNbZr samples, and $\mathrm{CN}$ values change monotonously and gently with the compositional variation, representing no unique structural character in the $\mathrm{Ni}_{62} \mathrm{Nb}_{33} \mathrm{Zr}_{5}$ BMG composition, which has been confirmed to have a local GFA maximum [31]. This indicates that dependence of the GFA on the $\mathrm{Zr}$ doping in $\mathrm{NiNb}$ alloy system can not be explained by such atomic-level structure analysis.

Via Voronoi-tessellation approach, we can obtain cluster-level structural information. VCs can be extracted from the RMC simulated structural models, and 
indexed based on their geometrical features. The major VCs centered with $\mathrm{Ni}, \mathrm{Nb}$, and $\mathrm{Zr}$ atoms are plotted in Figs. 4 (a)-4(c). Although the distributions of Ni-centered VCs looks similar between these five samples, there is noticeable distribution discrepancies of the $\mathrm{Nb}(\mathrm{Zr})$ centered $\mathrm{VCs}$ between these $\mathrm{NiNbZr}$ compositions. For instance, the fractions of $\mathrm{Zr}$-centered VCs indexed as $\langle 0,0,12,0\rangle$ and $\langle 0,2,8,3\rangle$ in $\mathrm{Ni}_{62} \mathrm{Nb}_{33} \mathrm{Zr}_{5}$ are much higher than those in other four NiNbZr compositions, while such values of $\langle 0,3,6,3\rangle$ and $\langle 0,3,6,4\rangle$ in $\mathrm{Ni}_{62} \mathrm{Nb}_{33} \mathrm{Zr}_{5}$ are smaller than their counterparts in $\mathrm{Ni}_{62} \mathrm{Nb}_{38-\mathrm{x}} \mathrm{Zr}_{\mathrm{x}}(\mathrm{x}=1,3,7$, and 9). In addition, $\mathrm{Nb}$-centered $<0,2,8,3>$, $<0,1,10,2>$, and $<0,1,10,3>\mathrm{VCs}$ have the relatively high weights in $\mathrm{Ni}_{62} \mathrm{Nb}_{33} \mathrm{Zr}_{5}$.

$\langle 0,0,12,0\rangle \mathrm{VC}$ is the so-called ideal icosahedron, which is regarded as the popular short-range ordering which is helpful to glass formation in alloys [45-48]. Therefore, it is reasonable that $\mathrm{Ni}_{62} \mathrm{Nb}_{33} \mathrm{Zr}_{5}$ has relatively high weight of $\mathrm{Zr}$-centered $<0,0,12,0\rangle \mathrm{VC}$, considering $\mathrm{Ni}_{62} \mathrm{Nb}_{33} \mathrm{Zr}_{5}$ has the local GFA maximum among the five compositions [31]. However, why does $\mathrm{Ni}_{62} \mathrm{Nb}_{33} \mathrm{Zr}_{5}$ has the relatively high (or small) fractions of $\mathrm{Zr}$-centered $\langle 0,2,8,3\rangle,\langle 0,3,6,3\rangle$, and $\langle 0,3,6,4\rangle \mathrm{VCs}$, and $\mathrm{Nb}$-centered $\langle 0,2,8,3\rangle,\langle 0,1,10,2\rangle$, and $\langle 0,1,10,3\rangle$ VCs? For disorder systems, it has been proposed that only stacking icosahedral clusters can not fill space with an efficiency as high as in corresponding quasicrystals, i.e., structural frustration [49]. In fact, in various work studying the local structures of amorphous alloys, it has been confirmed that besides the ideal icosahedron (or distorted icosahedron), various clusters also are the structural components forming amorphous structure [29,30,40].

According to the Voronoi algorithm, each VC and its corresponding VP (relation between a VP and its corresponding VP refers to Fig. 1) can be indexed as $<\mathrm{n} 3, \mathrm{n} 4, \mathrm{n} 5, \mathrm{n} 6\rangle$, where $n i$ denotes the number of the i-edged faces in a VP and the number of i-connected shell atoms in a VC $[29,40,42]$. For instance, in a $\langle 0,0,12,0\rangle$ 
VP (n5 = 12) and corresponding VC, there are 12 pentagons and 12 five-connected shell atoms, respectively; in a $\langle 0,1,10,2\rangle \mathrm{VP}$ and corresponding $\mathrm{VC}$, there are 1 quadrangle, 10 pentagons, and 2 hexagons, and 1 four-connected, 10 five-connected, and six-connected shell atoms, respectively. Unit cells are the basic structural components to form long range translational periodicity in crystals. Although icosahedral clusters do occur in many crystalline alloys, periodically stacking icosahedra which possess abundant five-fold symmetries to fill space is strictly forbidden in crystals [50]. We have pointed out that an ideal icosahedron cluster contains 12 five-connected shell atoms, thus, we suppose that clusters with abundant five-connected shell atoms might not favor the formation of crystals. It is well known that MGs can be obtained by fast quenching the liquid, bypassing the formation of corresponding crystalline phases. In previous work, five-fold symmetry has been confirmed to be a universal structural feature in glassy alloys [51]. In this work, a principle is thus proposed to estimate what VPs and their corresponding VCs should be preferred for formation of amorphous alloys (enhancing GFA), by calculating the weight (W) of five-connected shell atoms in clusters, according to the following equation:

$$
W=\frac{n_{5}}{n_{3}+n_{4}+n_{5}+n_{6}}
$$

We suppose that the larger $\mathrm{W}$ value is, the more favored in BMGs a VC is.

To clarify this scenario, VCs with relatively large $\mathrm{W}$ values $(>0.6$ here) are sorted out, whose fractions are listed in Table 3. For each <n3,n4,n5,n6> indexed VC, $\sum n i$ stands for the $\mathrm{CN}$ of its center atom, i.e., the number of the shell atoms in one VC. $\langle 0,2,8,1\rangle$ (corresponding to VCs with $\mathrm{CN}$ of 11 ), $\langle 0,0,12,0\rangle$ and $\langle 0,2,8,2\rangle$ 
(corresponding to VCs with $\mathrm{CN}$ of 12 ), $<0,1,10,2\rangle$ and $<0,2,8,3\rangle$ (corresponding to VCs with $\mathrm{CN}$ of 13), <0,1,10,3> (corresponding to VCs with $\mathrm{CN}$ of 14), and $<0,1,10,4>$ (corresponding to $\mathrm{VC}$ with $\mathrm{CN}$ of 15 ) have the relatively large $\mathrm{W}$ values (>0.6) that they can be regarded as the preferred clusters. Configurations of these seven preferred clusters are plotted in Fig. 5. Fractions of the preferred clusters (corresponding to $\mathrm{CNs}$ of $11,12,13$, and 14) centered with $\mathrm{Ni}, \mathrm{Nb}$, or $\mathrm{Zr}$ atoms are listed in Table 3. It seems that the $\mathrm{W}$ values for Ni-centered VCs is not sensitive to $\mathrm{Zr}$-doping, probably because $\mathrm{Nb}$ atoms rather than $\mathrm{Ni}$ atoms are replaced by $\mathrm{Zr}$ atoms. It is interesting that almost all the tabulated weights for both $\mathrm{Nb}$ - and $\mathrm{Zr}$-centered $\mathrm{VCs}$ have the highest values in the $\mathrm{Ni}_{62} \mathrm{Nb}_{33} \mathrm{Zr}_{5}$, which is just the composition having the local maximum of GFA [31]. Thus, these results indicate that if a VC (such as the ideal icosahedron, $\langle 0,0,12,0\rangle)$ has a high fraction of the five-connected shell atoms, this cluster might be the favorable structural building block, contributing to the GFA of MGs. Although glass formation might be affected by various structural factors, the W proposed here should be a structural parameter directly indicating the GFA in alloys.

\section{Conclusion}

In summary, the microstructure of $\mathrm{Ni}_{62} \mathrm{Nb}_{38-\mathrm{x}} \mathrm{Zr}_{\mathrm{x}}(\mathrm{x}=1,3,5,7$, and 9) alloys are investigated by calculations based on the data obtained from synchrotron radiation XRD and EXAFS experiments. It is revealed that microalloying of $\mathrm{Zr}$ atoms in the $\mathrm{NiNb}$ binary alloys gives rise to a number of Voronoi-tessellation clusters (local structures) which have high fraction of five-connected shell atoms, and these clusters are favored in the microstructure of glassy alloy. This can stabilize the amorphousstate structural stability, and the GFA is enhanced accordingly. This work will shed new light on the microalloying effect on the GFA of multicomponent MGs. 


\section{Acknowledgments}

The authors would like to thank the Shanghai Synchrotron Radiation Facility in

China, the Advanced Photon Source in USA, and the National Synchrotron Radiation Laboratory in China for the use of the advanced synchrotron radiation facilities. Financial supports from the National Natural Science Foundation of China (Grant No. 51471088 and U1332112), the Fundamental Research Funds for the Central Universities (Grant No. NE2015004), the Funding for Outstanding Doctoral Dissertation in NUAA (Grant No. BCXJ12-08), the Funding of Jiangsu Innovation Program for Graduate Education (Grant No. CXLX13-152), the project funded by the Priority Academic Program Development (PAPD) of Jiangsu Higher Education Institutions, the US Department of Energy - Basic Energy Sciences, the Canadian Light Source and its funding partners, and the U.S. DOE (Grant No. DE-AC0206CH11357) are gratefully acknowledged.

\section{References}

1 A. Inoue, Stabilization of metallic supercooled liquid and bulk amorphous alloys, Acta Mater. 48 (2000) 279-306.

2 D. Turnbull, Under what conditions can a glass be formed? Contmp. Phys. 10 (1969) 473-488.

3 A.L. Greer, Confusion by design, Nature 366 (1993) 303-304.

4 W.L. Johnson, Bulk glass-forming metallic alloys: Science and technology, MRS Bull. 24 (1999) 42-56.

5 Z.P. Lu, C.T. Liu, Glass formation criterion for various glass-forming systems, Phys. Rev. Lett. 91 (2003) 115505.

6 H.B. Yu, Y.S. Luo, K. Samwer, Ultrastable metallic glass, Adv. Mater. 25 (2013) 5904-5908. 
7 J. Schroers, Bulk metallic glasses, Phys. Today 66 (2013) 32-37.

8 C. Suryanarayana, A. Inoue, Iron-based bulk metallic glasses, Int. Mater. Rev. 58 (2013) 131-166.

9 L. Zhong, J.W. Wang, H.W. Sheng, Z. Zhang, S.X. Mao, Formation of monatomic metallic glasses through ultrafast liquid quenching, Nature 512 (2014) 177-180.

10 S.Y. Ding, Y.H. Liu, Y.L. Li, Z. Liu, S. Sohn, F.J. Walker, J. Schroers, Combinatorial development of bulk metallic glasses, Nature Commun. 13 (2014) 494-500.

11 J.H. Na, Demetriou, M.D. Demetriou, M. Floyd, A. Hoff, G.R. Garrett, W.L. Johnson, Compositional landscape for glass formation in metal alloys, Proc. Natl. Acad. Sci. U.S.A. 111 (2014) 9031-9036.

12 Y. Li, Q. Guo, J.A. Kalb, C.V. Thompson, Matching glass-forming ability with the density of the amorphous phase, Science 322 (2008) 1816-1819.

13 Z.P. Lu, C. T. Liu, Role of minor alloying additions in formation of bulk metallic glasses: a review, J. Mater. Sci. 39 (2004) 3965-3974.

14 W.H. Wang, Roles of minor additions in formation and properties of bulk metallic glasses, Prog. Mater. Sci. 52 (2007) 540-596.

15 D.H. Xu, G. Duan, W.L. Johnson, Unusual glass-forming ability of bulk amorphous alloys based on ordinary metal copper, Phys. Rev. Lett. 92 (2004) 245504.

16 D. Wang, H. Tan, Y. Li, Multiple maxima of GFA in three adjacent eutectics in $\mathrm{Zr}-\mathrm{Cu}-\mathrm{Al}$ alloy system-A metallographic way to pinpoint the best glass forming alloys, Acta Mater. 53 (2005) 2969-2979.

17 Q.S. Zhang, W. Zhang, A. Inoue, Preparation of $\mathrm{Cu}_{36} \mathrm{Zr}_{48} \mathrm{Ag}_{8} \mathrm{Al}_{8}$ bulk metallic 
glass with a diameter of $25 \mathrm{~mm}$ by copper mold casting, Mater. Trans. 48 (2007) $629-631$.

18 L.Y. Chen, Z.D. Fu, G.Q. Zhang, X.P. Hao, Q.K. Jiang, X.D. Wang, Q.P. Cao, H. Franz, Y.G. Liu, H.S. Xie, S.L. Zhang, B.Y. Wang, Y.W. Zeng, J.Z. Jiang, New class of plastic bulk metallic glass, Phys. Rev. Lett. 100 (2008) 075501.

19 J.L. Wu, W.H. Li, Y. Pan, J.Y. Qi, J.G. Wang, Microalloying and microstructures of $\mathrm{Cu}$-based bulk metallic glasses \& composites and relevant mechanical properties, Mater. Des. 89 (2016) 1130-1136.

20 T. Egami, Y. Waseda, Atomic size effect on the formability of metallic glasses, J. Non-Cryst. Solids 64 (1984) 113-134.

21 A. Hirata, P.F. Guan, T. Fujita, Y. Hirotsu, A. Inoue, A.R. Yavari, T. Sakurai, M.W. Chen, Direct observation of local atomic order in a metallic glass, Nature Mater. 10 (2011) 28-33.

22 I. Kaban, P. Jovari, V. Kokotin, Q. Shuleshova, B. Beuneu, K. Saksl, N. Mattern, J. Eckert, A.L. Greer, Local atomic arrangements and their topology in Ni-Zr and $\mathrm{Cu}-\mathrm{Zr}$ glassy and crystalline alloys, Acta Mater. 61 (2013) 2509-2520.

23 A.H. Cai, D.W. ding, X. Xiong, Y. Liu, W.K. An, G.J. Zhou, Y. Luo, T.L. Li, X.S. Li, Design of Zr-Al-Ni-Cu bulk metallic glasses with network structures, Mater. Des. 63 (2014) 233-237.

24 J. Ding, Y.Q. Cheng, E. Ma, Full icosahedra dominate local order in $\mathrm{Cu}_{64} \mathrm{Zr}_{34}$ metallic glass and supercooled liquid, Acta Mater. 69 (2014) 343-354.

25 Z.W. Wu, M.Z. Li, W.H. Wang, K.X. Liu, Hidden topological order and its correlation with glass-forming ability in metallic glasses, Nature Commun. 6 (2015) 6035 .

26 J.D. Bernal, A geometrical approach to the structure of liquids, Nature 183, (1959) 
$141-147$.

27 P.H. Gaskell, A new structural model for transition metal-metalloid glasses, Nature 276 (1978) 484-485.

28 D.B. Miracle, A structural model for metallic glasses, Nature Mater. 3, (2004) 697-702.

29 H.W. Sheng, W.K. Luo, F.M. Alamgir, J.M. Bai, E. Ma, Atomic packing and short-to-medium-range order in metallic glasses, Nature 439 (2006) 419-425.

30 L. Yang, G.Q. Guo, L.Y. Chen, C.L. Huang, T. Ge, D. Chen, P.K. Liaw, K. Saksl, Y. Ren, Q.S. Zeng, B. LaQua, F.G. Chen, J. Z. Jiang, Atomic-scale mechanisms of the glass-forming ability in metallic glasses, Phys. Rev. Lett. 109 (2012) 105502.

31 L.Y. Chen, H.T. Hu, G.Q. Zhang, J.Z. Jiang, Catching the Ni-based ternary metallic glasses with critical diameter up to $3 \mathrm{~mm}$ in $\mathrm{Ni}-\mathrm{Nb}-\mathrm{Zr}$ system, J. Alloys Compd. 443, (2007) 109-113.

32 Z.W. Zhu, H.F. Zhang, B.Z. Ding, Z.Q. Hu, Synthesis and properties of bulk metallic glasses in the ternary $\mathrm{Ni}-\mathrm{Nb}-\mathrm{Zr}$ alloy system, Mater. Sci. Eng. A 492, (2008) 221-229.

33 A.P. Hammersley, S.O. Svensson, M. Hanfland, A.N. Fitch, D. Häusermann, Two-dimensional detector software: from real detector to idealised image or twotheta scan, High Pressure Res. 14 (1996) 235-248.

34 X. Qiu, J.W. Thompson, PDFgetX2: a GUI-driven program to obtain the pair distribution function from X-ray powder diffraction data, J. Appl. Cryst. 37 (2004) 678.

35 K.V. Klementev, Extraction of the fine structure from x-ray absorption spectra, J. Phys. D 34 (2001) 209-217. 
36 R.L. McGreevy, L. Pusztai, Reverse Monte Carlo simulation: a new technique for the determination of disordered structures, Mol. Simulation. 1 (1988) 359-367.

37 L. Pusztai, E. Svab, Structure study of $\mathrm{Ni}_{62} \mathrm{Nb}_{38}$ metallic glass using reverse Monte Carlo simulation, J. of Non-Crystal. Solids 156 (1993) 973-977.

38 R.L. McGreevy, Reverse Monte Carlo modeling, J. Phys. Condens. Matter. 13 (2001) R877-913.

39 K. Saksl, P. Jovari, H. Franz, Q.S. Zeng, J.F. Liu, J.Z. Jiang, Atomic structure of $\mathrm{Al}_{89} \mathrm{La}_{6} \mathrm{Ni}_{5}$ metallic glass, J. Phys. Condens. Matter. 18 (2006) 7579-7592.

40 S.Y. Wang, M.J. Kramer, M. Xu, S. Wu, S.G. Hao, D.J. Sordelet, K.M. Ho, C.Z. Wang, Experimental and ab initio molecular dynamics simulation studies of liquid $\mathrm{Al}_{60} \mathrm{Cu}_{40}$ alloy, Phys. Rev. B 79 (2009) 144205.

41 T. Fugunaga, K. Itoh, T. Otomo, K. Mori, M. Sugiyama, H. Kato, M. Hasegawa, A. Hirata, Y. Hirotsu, A.C. Hannon, Voronoi analysis of the structure of $\mathrm{Cu}-\mathrm{Zr}$ and Ni-Zr metallic glasses, Intermetal. 14 (2006) 893-897.

42 L. Yang. G.Q. Guo, Preferred clusters in metallic glasses, Chin. Phys. B 12 (2010) 126101.

43 Q.S. Zeng, H.W. Sheng, D. Yang, L. Wang, W.G. Yang, J.Z. Jiang, W.L. Mao, H.K. Mao, Long-range topological order in metallic glass, Science 332 (2011) 1404-1406.

44 B. Ravel, M. Newville, ATHENA, ARTEMIS, HEPHAESTUS: data analysis for X-ray absorption spectroscopy using IFEFFIT, J. Synch. Rad. 12 (2005) 537-541.

45 K. Saksl, H. Franz, P. Jovari, K. Klementiev, E. Welter, A. Ehnes, J. Saida. A. Inoue, J.Z. Jiang, Evidence of icosahedral short-range order in $\mathrm{Zr}_{70} \mathrm{Cu}_{30}$ and $\mathrm{Zr}_{70} \mathrm{Cu}_{29} \mathrm{Pd}_{1}$ metallic glasses, Appl. Phys. Lett. 83 (2004) 3924.

46 W.K. Luo, H.W. Sheng, F.M. Alamgir, J.M. Bai, J.H. He, E. Ma, Icosahedral 
short-range order in amorphous alloys, Phys. Rev. Lett. 92 (2004) 145502.

47 Y.T. Shen, T.H. Kim, A.K. Gangopadhyay, K.F. Kelton, Icosahedral order, frustration, and the glass transition: Evidence from time-dependent nucleation and supercooled liquid structure studies, Phys. Rev. Lett. 102 (2009) 057801.

48 Y.Q. Cheng, E. Ma, H.W. Sheng, Atomic level structure in multicomponent bulk metallic glass, Phys. Rev. Lett. 102 (2009) 245501.

49 A. Hirata, L.J. Kang, T. Fujita, B. Klumov, K. Matsue, M. Kotani, A.R. Yavari, M.W. Chen, Geometric frustration of icosahedron in metallic glasses, Science 341 (2013) 376-379.

50 D. Schwarzenbach, Crystallography, John Wiley and Sons, Inc. (1996).

51 Y.C. Hu, F.X. Li, M.Z. Li, H.Y. Bai, W.H. Wang, Five-fold symmetry as indicator of dynamic arrest in metallic glass-forming liquids, Nature Commun. 6 (2015) 8310. 
Table Caption

Table 1 The coordination numbers (CNs) around $\mathrm{Ni}, \mathrm{Nb}$, and $\mathrm{Zr}$ center atoms, respectively, which are obtained via the $\mathrm{RMC}$ simulation. There is no $\mathrm{Zr}-\mathrm{Zr}$ connections when 1 at.\% $\mathrm{Zr}$ is doped.

\begin{tabular}{cccccc}
\hline \hline Atomic pairs & \multicolumn{5}{c}{$\mathrm{CNs}( \pm 0.05)$} \\
\cline { 2 - 6 } & $\mathrm{Ni}_{62} \mathrm{Nb}_{37} \mathrm{Zr}_{1}$ & $\mathrm{Ni}_{62} \mathrm{Nb}_{35} \mathrm{Zr}_{3}$ & $\mathrm{Ni}_{62} \mathrm{Nb}_{33} \mathrm{Zr}_{5}$ & $\mathrm{Ni}_{62} \mathrm{Nb}_{31} \mathrm{Zr}_{7}$ & $\mathrm{Ni}_{62} \mathrm{Nb}_{29} \mathrm{Zr}_{9}$ \\
\hline $\mathrm{Ni}-\mathrm{Ni}$ & 7.47 & 7.42 & 7.40 & 7.39 & 7.32 \\
$\mathrm{Ni}-\mathrm{Nb}$ & 5.12 & 4.83 & 4.46 & 4.14 & 3.93 \\
$\mathrm{Ni}-\mathrm{Zr}$ & 0.14 & 0.40 & 0.71 & 0.98 & 1.25 \\
Total of Ni & 12.7 & 12.6 & 12.6 & 12.5 & 12.5 \\
$\mathrm{Nb}-\mathrm{Ni}$ & 8.62 & 8.61 & 8.40 & 8.30 & 8.40 \\
$\mathrm{Nb}-\mathrm{Nb}$ & 4.61 & 4.27 & 4.05 & 3.71 & 3.48 \\
$\mathrm{Nb}-\mathrm{Zr}$ & 0.11 & 0.37 & 0.59 & 0.83 & 1.08 \\
Total of Nb & 13.3 & 13.3 & 13.1 & 12.8 & 12.9 \\
$\mathrm{Zr}-\mathrm{Ni}$ & 8.97 & 8.68 & 8.94 & 8.62 & 8.66 \\
$\mathrm{Zr}-\mathrm{Nb}$ & 4.50 & 4.43 & 3.84 & 3.75 & 3.50 \\
$\mathrm{Zr}-\mathrm{Zr}$ & & 0.23 & 0.37 & 0.60 & 0.86 \\
Total of $\mathrm{Zr}$ & 13.5 & 13.3 & 13.2 & 13.0 & 13.0 \\
\hline \hline
\end{tabular}

Table 2 The first-shell atomic pair distances (APDs) for all the atomic pairs in the selected MGs. As a contrast, $\mathrm{D}_{\mathrm{SGAR}}$ is adopted, which is the interatomic distance calculated from the sum of Goldschmidt atomic radii (SGAR). There is no $\mathrm{Zr}-\mathrm{Zr}$ connections when 1 at. $\% \mathrm{Zr}$ is doped.

\begin{tabular}{ccccccc}
\hline \hline Atomic & \multicolumn{5}{c}{$\mathrm{APDs}(\AA)$} & \multirow{2}{*}{$\mathrm{D}_{\mathrm{SGAR}}(\AA)$} \\
\cline { 2 - 6 } pairs & $\mathrm{Ni}_{{ }_{62} \mathrm{Nb}_{37} \mathrm{Zr}_{1}}$ & $\mathrm{Ni}_{62} \mathrm{Nb}_{35} \mathrm{Zr}_{3}$ & $\mathrm{Ni}_{62} \mathrm{Nb}_{33} \mathrm{Zr}_{5}$ & $\mathrm{Ni}_{62} \mathrm{Nb}_{31} \mathrm{Zr}_{7}$ & $\mathrm{Ni}_{62} \mathrm{Nb}_{29} \mathrm{Zr}_{9}$ & \\
\hline $\mathrm{Ni}-\mathrm{Ni}$ & 2.56 & 2.57 & 2.57 & 2.56 & 2.57 & 2.52 \\
$\mathrm{Ni}-\mathrm{Nb}$ & 2.73 & 2.73 & 2.74 & 2.73 & 2.71 & 2.69 \\
$\mathrm{Ni}-\mathrm{Zr}$ & 2.83 & 2.84 & 2.84 & 2.83 & 2.84 & 2.84 \\
$\mathrm{Nb}-\mathrm{Nb}$ & 2.85 & 2.84 & 2.85 & 2.83 & 2.85 & 2.86 \\
$\mathrm{Nb}-\mathrm{Zr}$ & 2.91 & 2.89 & 2.89 & 2.89 & 2.90 & 2.86 \\
$\mathrm{Zr}-\mathrm{Zr}$ & & 3.13 & 3.15 & 3.14 & 3.13 & 3.20 \\
\hline \hline
\end{tabular}

Table 3 Concentrations of the preferred VCs (see Fig. 5) centered with $\mathrm{Ni}, \mathrm{Nb}$, or $\mathrm{Zr}$ atoms. Because the $\mathrm{CNs}$ of $\mathrm{Ni}-, \mathrm{Nb}-$, and $\mathrm{Zr}$-centered VCs mainly rang from 11, 12 , and 12 to 13, 14, and 14, respectively (see Fig. 4), here their corresponding values are 
tabulated. Note that over a dozen different kinds of VCs with the same CN $(11,12,13$, 14,15 , and so on) can be extracted and indexed. Here the tabulated values are the weights of some preferred VCs in all the deduced VCs with the same CNs.

\begin{tabular}{ccccccc}
\hline \hline \multirow{2}{*}{$\begin{array}{c}\text { Types } \\
\text { of VCs }\end{array}$} & CN of & \multicolumn{5}{c}{ Weights of the preferred VCs (\%) } \\
\cline { 3 - 7 } & $\mathrm{VCs}$ & $\mathrm{Ni}_{62} \mathrm{Nb}_{37} \mathrm{Zr}_{1}$ & $\mathrm{Ni}_{62} \mathrm{Nb}_{35} \mathrm{Zr}_{3}$ & $\mathrm{Ni}_{62} \mathrm{Nb}_{33} \mathrm{Zr}_{5}$ & $\mathrm{Ni}_{62} \mathrm{Nb}_{31} \mathrm{Zr}_{7}$ & $\mathrm{Ni}_{62} \mathrm{Nb}_{29} \mathrm{Zr}_{9}$ \\
\hline \multirow{2}{*}{$\mathrm{Ni}^{-}$} & 11 & 45.38 & 44.07 & 44.25 & 42.43 & 41.98 \\
centered & 12 & 41.80 & 41.12 & 40.87 & 38.42 & 38.81 \\
& 13 & 18.38 & 18.84 & 19.14 & 17.48 & 17.73 \\
\multirow{2}{*}{$\mathrm{Nb}-$} & 12 & 45.73 & 44.45 & 42.81 & 42.25 & 43.96 \\
centered & 13 & 35.43 & 35.41 & 55.14 & 36.04 & 36.29 \\
& 14 & 12.07 & 11.83 & 24.25 & 12.38 & 11.70 \\
\multirow{2}{*}{$\mathrm{Zr}-$} & 12 & 38.30 & 50.98 & 59.69 & 35.97 & 33.61 \\
centered & 13 & 39.21 & 35.36 & 51.09 & 33.66 & 34.16 \\
& 14 & 10.20 & 9.22 & 14.22 & 12.70 & 13.19 \\
\hline \hline
\end{tabular}


Figure Caption

Figure 1 Configurations of a typical icosahedral VC $(<0,0,12,0\rangle)$ and its corresponding VP. For a $\langle 0,0,12,0\rangle$ index, its VP has 12 pentagons which are the middle sections between the center and a shell atom in the corresponding $\mathrm{VC}$, and there are 12 five-connected shell atoms in its VC.

Figure 2 (a) Structure factor, S(Q), (b) Total pair distribution function, G(r), (c) Ni Kedge, and (d) $\mathrm{Nb}$ K-edge EXAFS spectra. The solid and dashed lines denote experimental and simulation data, respectively. The $k$ and $\chi(k)$ represent the photoelectron wave vector and the k-space EXAFS signal, respectively.

Figure 3 All the partial pair distributions, $g(r) s$, obtained from the RMC simulation, including: (a) Ni-Ni, (b) Ni-Nb, (c) Ni-Zr, (d) Nb-Nb, (e) Nb-Zr, and (f) Zr-Zr.

Figure 4 Distribution of the major Voronoi clusters centered with (a) $\mathrm{Ni}$, (b) $\mathrm{Nb}$, and (c) $\mathrm{Zr}$ atoms. Coordination numbers here are the numbers of shell atoms surrounding the centers in VCs. Note only those whose fractions are larger than $1.5 \%$ are selected. $\mathrm{Zr} 1, \mathrm{Zr} 3, \mathrm{Zr} 5, \mathrm{Zr} 7$, and $\mathrm{Zr} 9$ stand for the $\mathrm{Ni}_{62} \mathrm{Nb}_{38-\mathrm{x}} \mathrm{Zr}_{\mathrm{x}}(\mathrm{x}=1,3,5,7$, and 9) compositions.

Figure 5 Configurations of seven VCs (ball and stick) which are favored in glassy alloys. All of them are VCs extracted from the RMC simulated models in the present work. Here to reflect their geometrical features more explicitly, $\mathrm{Zr}$ (the solute, red atom)-center and $\mathrm{Ni} / \mathrm{Nb}$ (the solvents, blue and celadon atoms)-shell VCs are selected. The number labeled on one shell atom stands for the number of its neighbor (connected) shell atoms. 


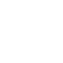

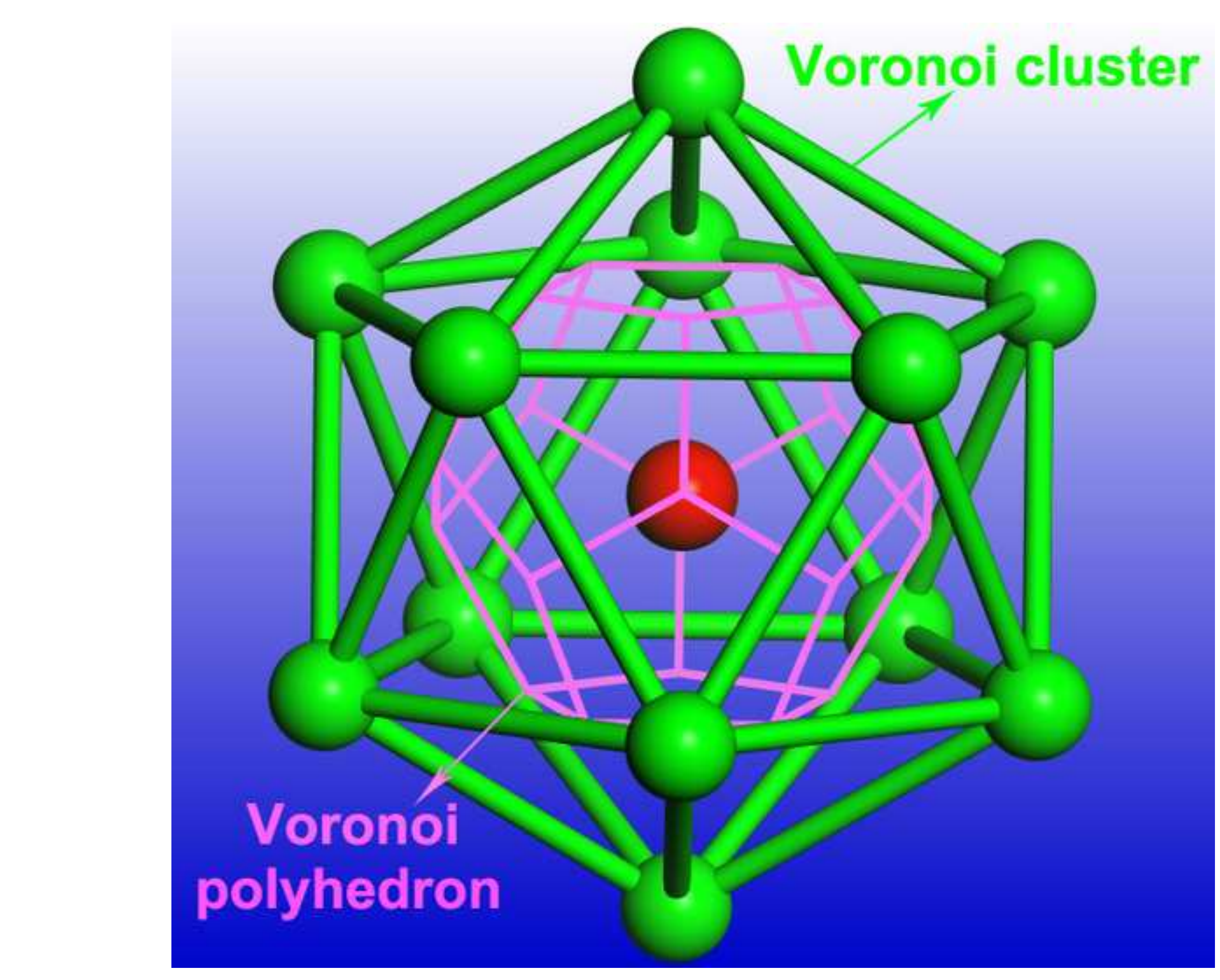

Voronoi polyhedron
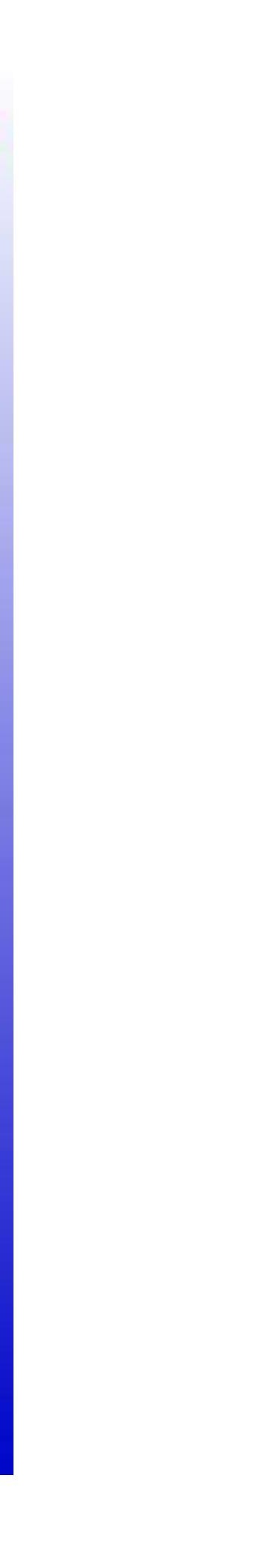

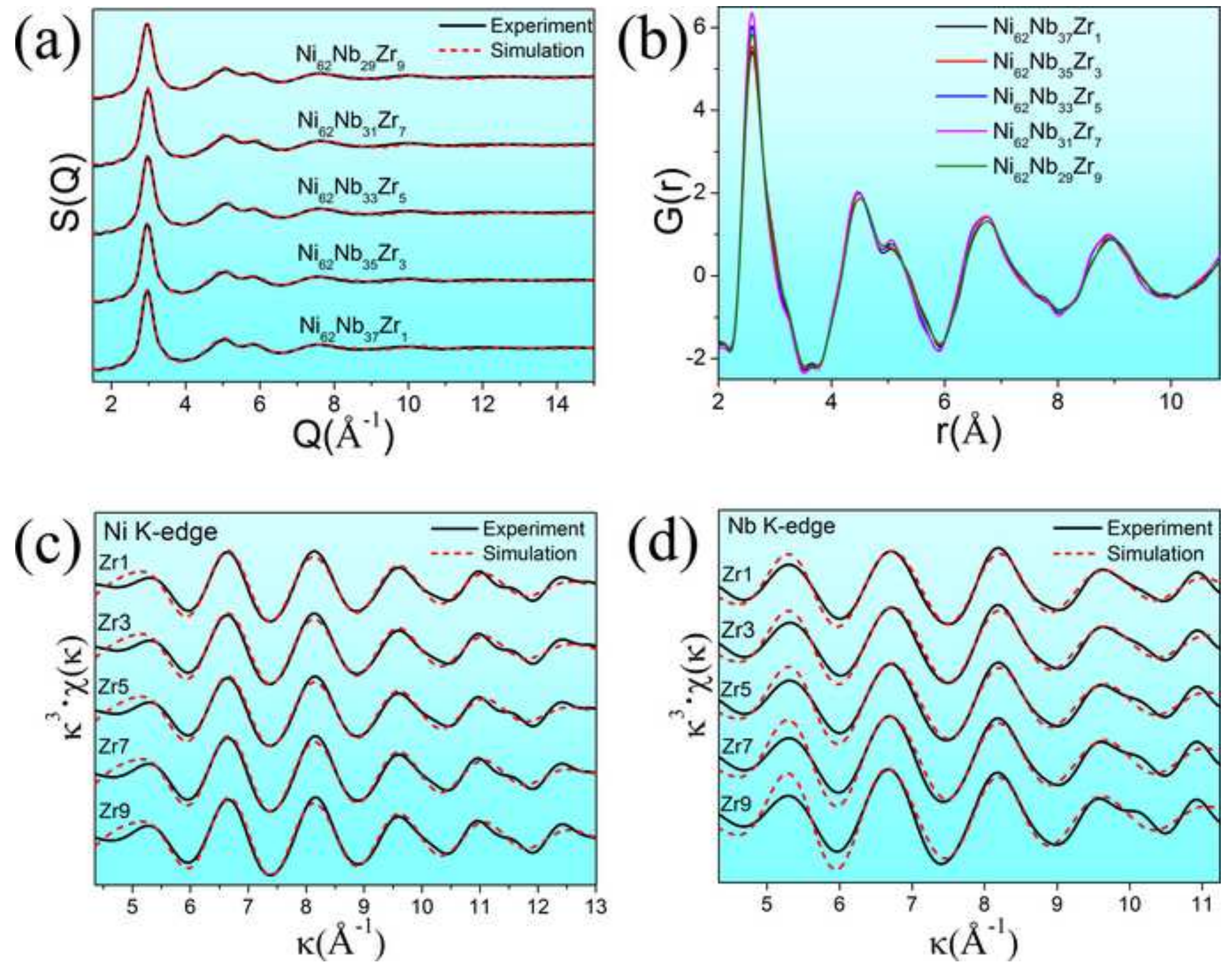

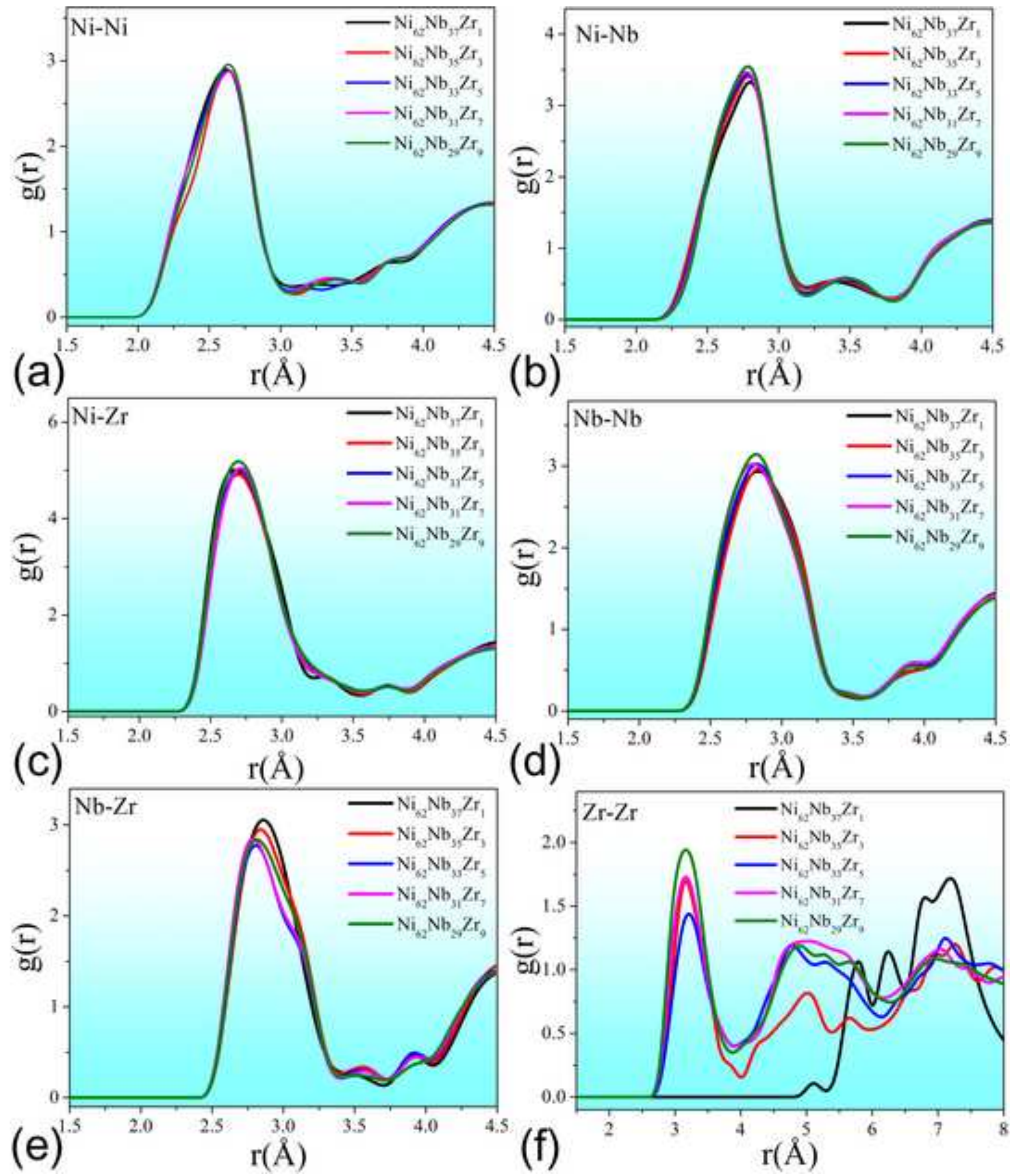
(a)

Coordination Number

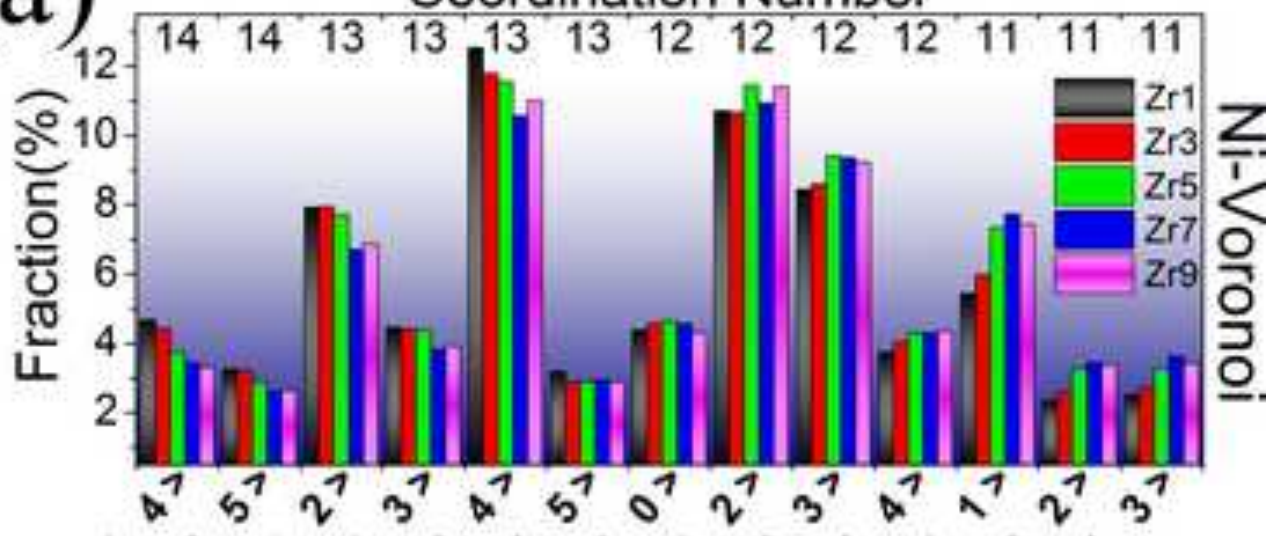

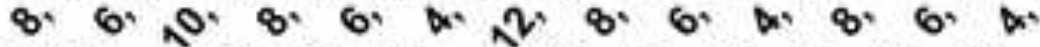

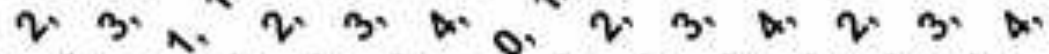

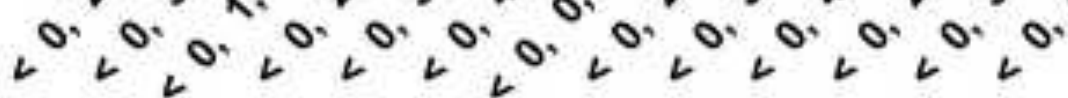

Voronoi Index

(b)

Coordination Number

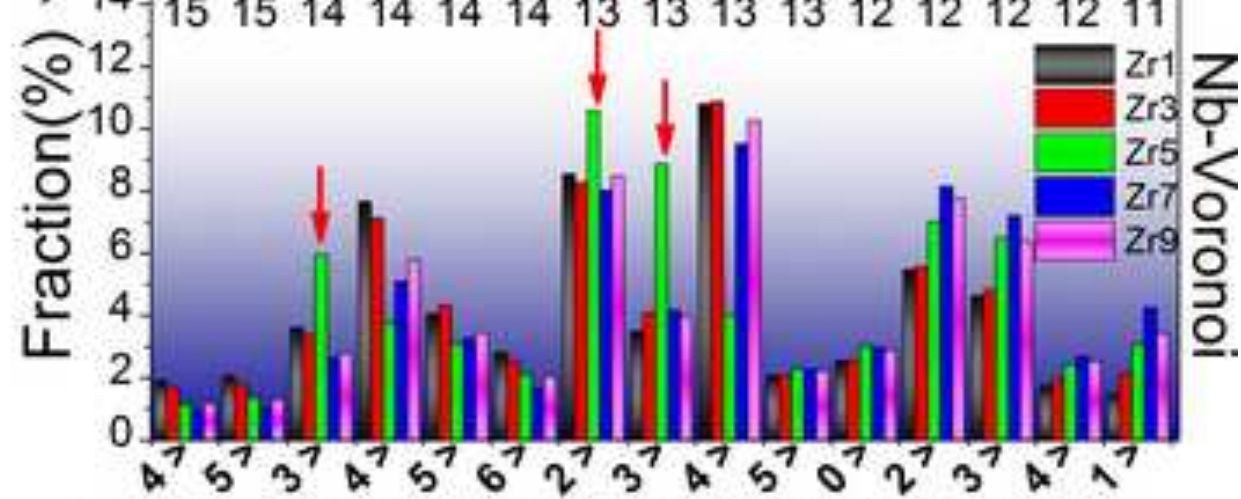

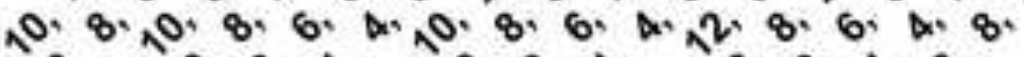

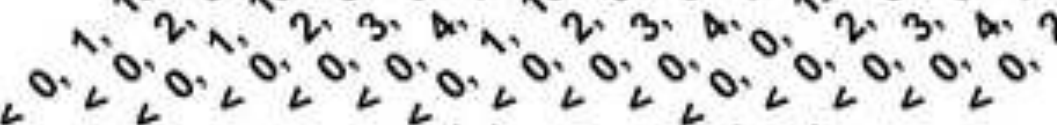

Voronoi Index

(C) Coordination Number

$14 \sqrt{1515141414141313131312121212111111}$

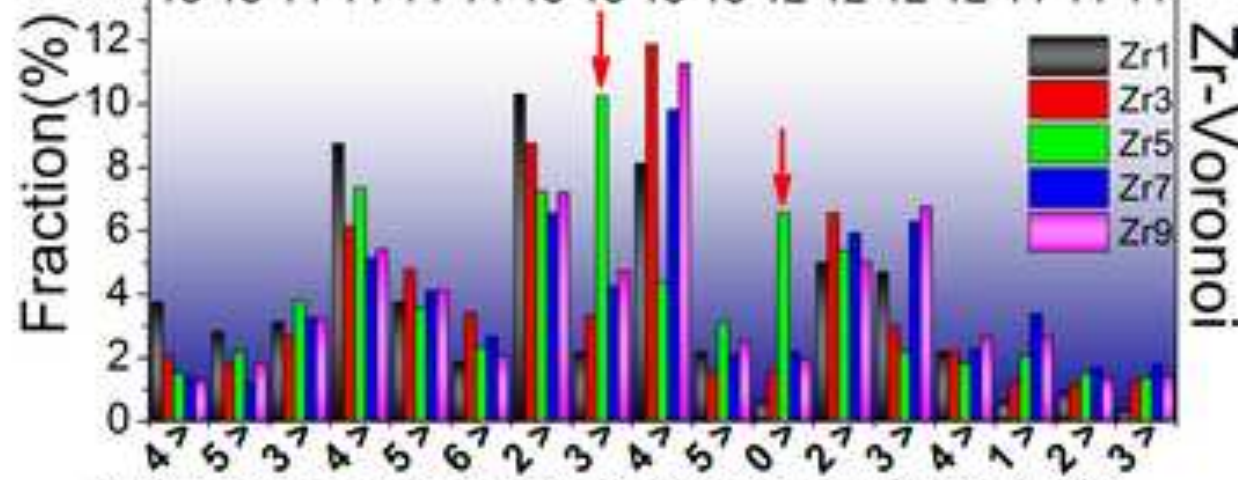

0.8.

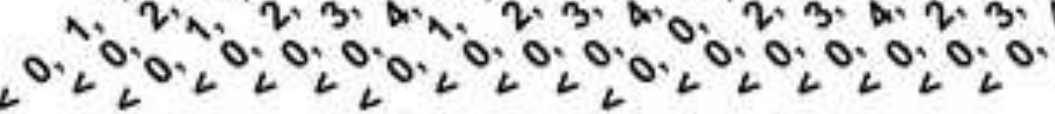

Voronoi Index 

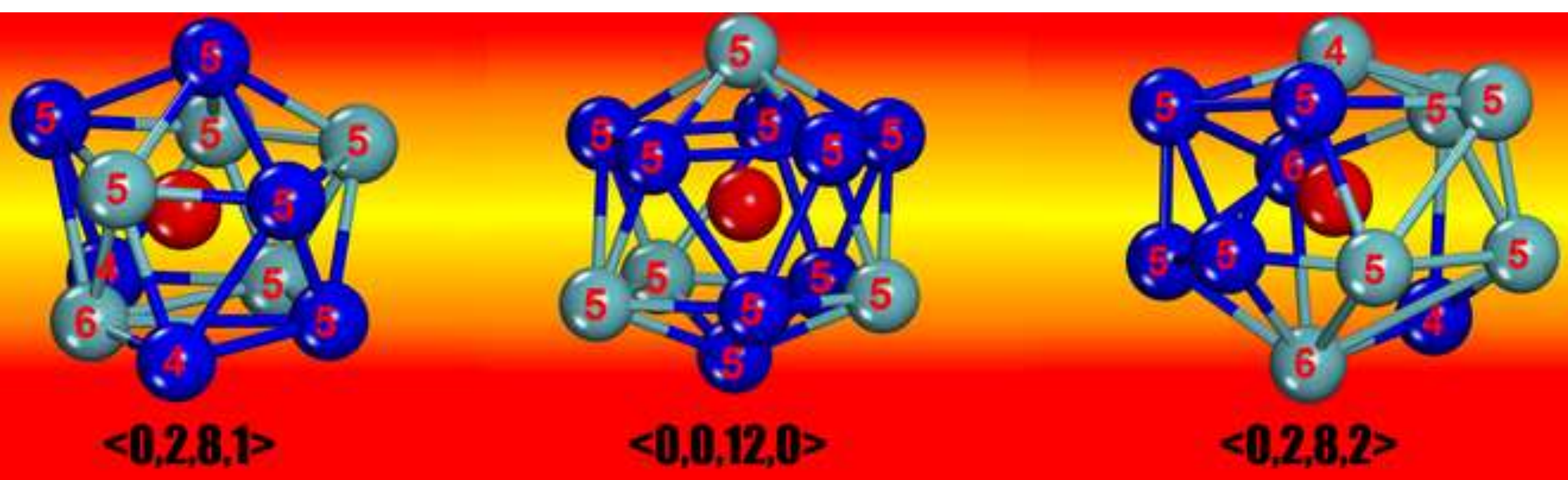

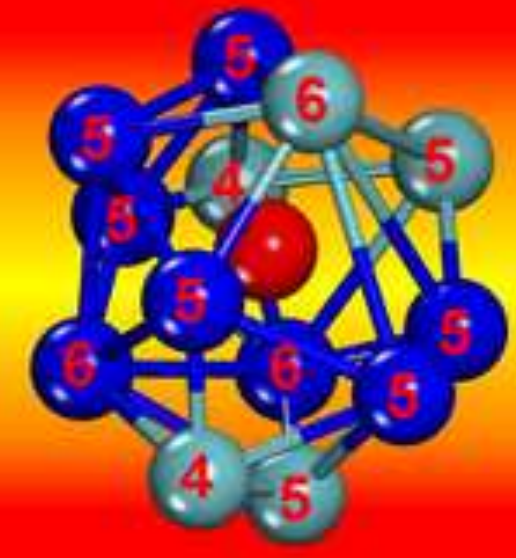

$<0,2,8,3>$

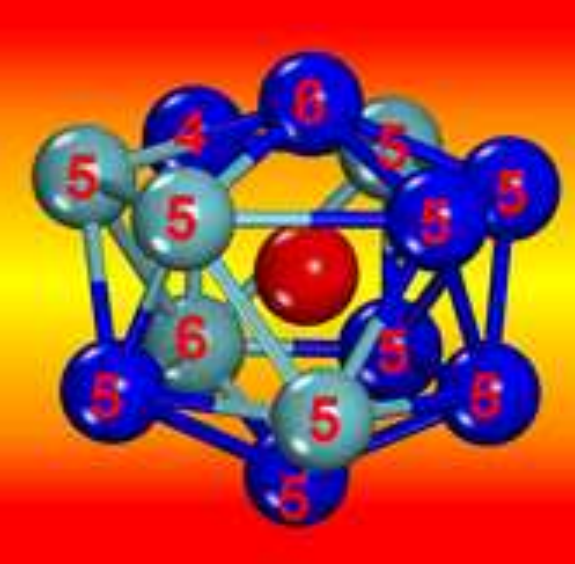

$\langle 0,1,10,2\rangle$

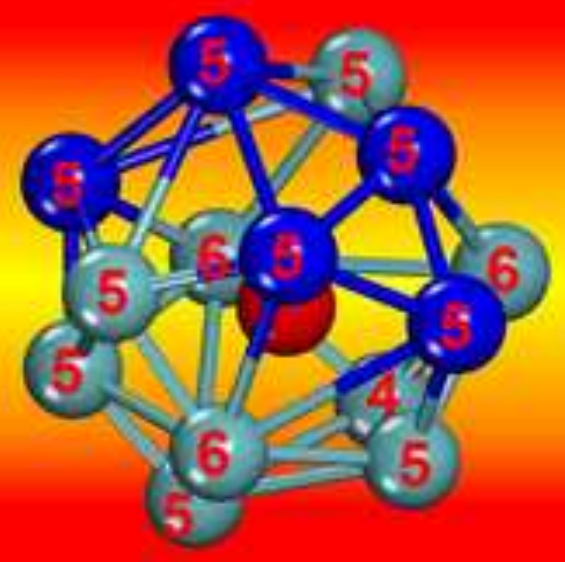

$<0,1,10,3\rangle$

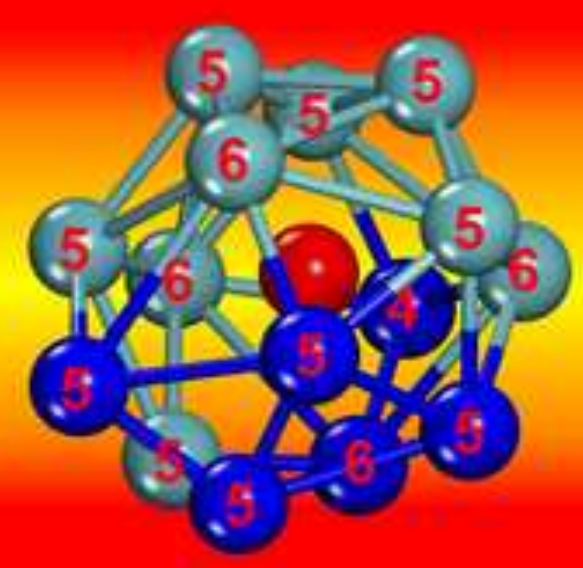

$\langle 0,1,10,4\rangle$ 


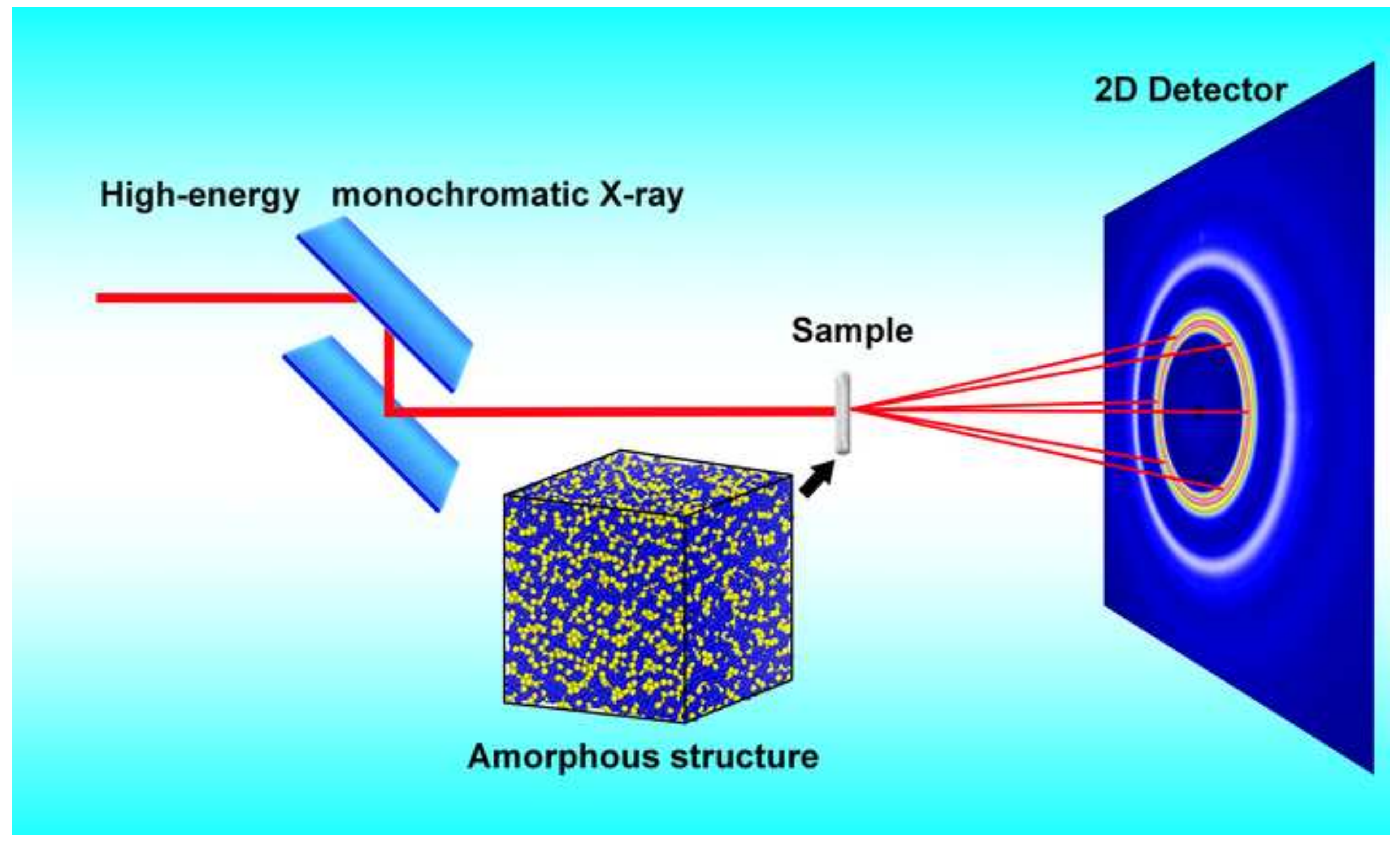

